\title{
Correction to: In vivo and in silico evaluation of analgesic activity of Lippia alba
}

Md. Abdullah Aziz ${ }^{1}$, Manna Mehedi ${ }^{2}$, Mst. Irin Akter ${ }^{2}$, Sadiur Rahman Sajon ${ }^{1 *}$, Kishor Mazumder ${ }^{1,3}$ and Md. Sohel Rana ${ }^{4}$

\section{Correction to: Clin Phytosci (2019) 5:38 https://doi.org/10.1186/s40816-019-0133-z}

In the original publication of this article [1], two authors' names are not complete. The author name "Irin Akter" should be revised to "Mst. Irin Akter", and "Sohel Rana" should be revised to "Md. Sohel Rana". In addition, author affiliation 2 and 4 should be revised to:

${ }^{2}$ Department of Pharmacy, Stamford University Bangladesh, 51, Siddeswari Road, Dhaka-1217, Bangladesh

${ }^{4}$ Department of Pharmacy. Jahangirnagar University, Savar, Dhaka-1342, Bangladesh

The original article has been corrected.

\section{Author details}

'Department of Pharmacy, Jashore University of Science and Technology, Jashore-7408, Jashore, Bangladesh. ${ }^{2}$ Department of Pharmacy, Stamford University Bangladesh, 51, Siddeswari Road, Dhaka 1217, Bangladesh. ${ }^{3}$ School of Biomedical Sciences, Charles Sturt University, Wagga Wagga, Australia. ${ }^{4}$ Department of Pharmacy, Jahangirnagar University, Savar, Dhaka 1342, Bangladesh.

Published online: 31 December 2019

\section{Reference}

1. Aziz M, et al. In vivo and in silico evaluation of analgesic activity of Lippia alba. Clin Phytosci. 2019;5:38

\footnotetext{
* Correspondence: sadiur.sajon@yahoo.com

The original article can be found online at https://doi.org/10.1186/s40816019-0133-z

'Department of Pharmacy, Jashore University of Science and Technology, Jashore-7408, Jashore, Bangladesh

Full list of author information is available at the end of the article
} 